\title{
Desenvolvimento de produto para consumidoras grávidas: reflexões por meio da roupa predileta
}

Product development for pregnant consumers : reflections through favorite clothes

\section{Nathilucy do Nascimento Marinho}

Pós-graduada lato sensu - Especialização em Produção de Moda e Styling pela Faculdade Senac/PE nathilucymarinho@gmail.com

\section{Maria Alice Vasconcelos Rocha}




\section{Desenvolvimento de produto para consumidoras grávidas: reflexões por meio da roupa predileta}

Product development for pregnant consumers : reflections through favorite clothes

Nathilucy do Nascimento Marinho e Maria Alice Vasconcelos Rocha

\section{Resumo}

Este trabalho é resultado de uma pesquisa que pretendeu compreender as relações existentes entre o vestuário e o estado gravídico das gestantes em idade adulta, assim como investigar a importância destas relações vestimentares com as alterações do corpo. Os dados foram gerados via os depoimentos de onze mulheres adultas em períodos gestacionais diversos, de modo que as informações foram tratadas por meio de métodos de análise qualitativa, em especial, as análises de conteúdo. Para a análise dos dados foram utilizados os Indicadores para o Consumo de ModaVestuário que foram trabalhados com as participantes da amostra através de: aplicação de questionários e entrevistas semiestruturadas, onde as gestantes comentaram sobre a sua Roupa Predileta. As relações exploradas nesse trabalho abrem caminho para a aplicação da Roupa Predileta como ferramenta para o desenvolvimento de novos produtos dedicados a públicos específicos.

Palavras- chave: Gestantes; Vestuário; Alterações Corporais

\begin{abstract}
This paper shows results of a research aimed to understand the relationship between clothing and the pregnancy state of women in adulthood, as well as to investigate the importance of these sartorial relationships with the changes of the body. The data were generated via the testimony of eleven adult women in different gestational stages, so that the information has been treated through methods of qualitative analysis, in particular, the content analysis. It was used the Indicators of Consumption for FashionClothing Products to collect via questionnaires and semi-structured interviews the sample participants' thoughts about their Favorite Clothes. The relationships found in this work suggest that the application of Favorite Clothing may be a successful tool for new product development dedicated to specific targets.
\end{abstract}

Keywords: Pregnant Women; Clothing; Bodily Changes 


\section{Introdução}

O corpo nos leva a descobrir dimensões imagináveis e inimagináveis da condição humana, da existência e essência do ser, apontando para o incerto, o exclusivo, o abrangente e até mesmo para a dúbia sensação da certeza. Inicialmente o desenvolvimento da vida humana acontece a partir do corpo feminino, pelo qual gradativamente modifica-se para acomodar um ser. No entanto, discutir esse assunto é complexo, pois há muitas ocorrências que interferem na visão do corpo gravídico como, por exemplo, as preocupações estéticas das gestantes.

Considerando as preocupações estéticas da mulher grávida, podemos destacar as principais alterações no comportamento e necessidades em seu cotidiano, como na alimentação, de se movimentar, e principalmente no vestuário que assume particularidades específicas de acordo com a individualidade de cada mulher.

Raras são as pesquisas que se dedicam ao desenvolvimento de produtos para usuários com necessidades especiais temporárias. Abordar uma reflexão sobre o corpo no período gestacional é a principal intenção desse estudo, sendo os principais objetivos entender as relações existentes entre o vestuário e o estado gravídico das gestantes em idade adulta e compreender a importância destas relações vestimentares com as alterações do corpo.

\section{Identificação Cultural do ato de Vestir}

O vestuário, sendo uma das formas mais visíveis de consumo, desempenha um papel de maior importância social na identidade de um indivíduo. A escolha de vestuário propicia um excelente campo de estudo sobre como as pessoas interpretam determinada forma de cultura para seu próprio uso (CRANE, 2006).

Certamente já aconteceu em um momento de nossas vidas a indagação a respeito da roupa que vamos vestir em um determinado ambiente. O produto-vestuário envolvese numa cadeia de questionamentos importantes, tais como: "eu posso", "eu quero", "eu sou"; que muitas das vezes são incompreendidos por nós, e intrinsecamente pertencentes à identidade humana. Por trás dessa atitude tão comum ao cotidiano de 
todas as pessoas, a escolha de determinadas peças inclui, além das características funcionais, a intenção de expressar o que esse indivíduo é ou deseja ser percebido (STEFANI, 2005).

Wilson (1985) descreve isso como uma questão da importância do vestuário para o indivíduo. As roupas, de uma maneira geral, parecem consequentemente preencher certo número de funções sociais, estéticas e psicológicas. Elas juntam-nas e expressamnas todas simultaneamente. As variações na escolha do vestuário constituem indicadores sutis de como são vivenciados os diferentes tipos de sociedade, assim como as diferentes posições dentro de uma mesma sociedade. De acordo com Crane (2006), as roupas podem ser vistas como um vasto reservatório de significados, passíveis de ser manipulados ou reconstruídos de forma a acentuar o senso pessoal da influência dos outros.

Com base nestes conceitos podemos afirmar que a roupa distingue e comunica determinados conjuntos de pessoas ou grupos sociais, por identificar, por si só, produtos da consciência, a partir de estímulos emitidos pelos objetos do mundo, neste caso, a roupa (ROCHA, 2010). Já Fisher-Mirkin (2001, p.17), declara que:

A vestimenta é a janela para o ser consciente e o inconsciente do homem. Nossa vestimenta revela muito de como nos sentimos em relação a nós mesmos e oferece um vislumbre de nossos desejos, nossas fantasias e nossos valores.

$\mathrm{O}$ autor ainda comenta a respeito dos significados de que a pessoa se veste:

A roupa ainda pode dar um suporte sutil à autoestima da mulher. As imagens constantes na mídia da mulher "ideal" conspiram contra todas nós, exceto as mais autoconfiantes, minando a segurança em nosso corpo (FISHER-MIRKIN, 2001, p. 17).

Entendemos, portanto, que em qualquer ambiente que estejamos, podemos transmitir infinitas mensagens através das roupas. E esses significados estão atrelados à personalidade das pessoas e aos seus contextos.

\section{Representações históricas do vestuário e do corpo}

Acredita-se que o corpo e o vestuário podem ser tratados como objetos de estudo, pois suas constituições e limitações enquanto objetos são fornecidos por alguns aspectos que durante a história acabaram influenciando-os. Na origem da Indumentária 
são encontradas três finalidades pelos quais a humanidade adotou o uso de roupas de acordo com Flügel (1966): proteção, pudor e enfeite.

Conforme Cidreira (2005) a proteção é um elemento essencial para se pensar nas variações das atitudes, frequentemente muito ambivalentes. $\mathrm{O}$ frio e os meios de defesa empregados para defender-se tem um papel primordial na civilização antiga. Já para Flügel (1966) além das roupas servirem para cobrir o corpo, satisfazendo, assim, o impulso do pudor, também e ao mesmo tempo, podem realçar a beleza do corpo (enfeite).

As palavras chave de interpretação do vestuário, pudor e proteção, encontram-se intimamente ligadas a perspectiva utilitarista e mesmo quando se desloca a explicação para o fenômeno da ornamentação, ainda aí, reconhecemos a inscrição a um campo de argumentação comum, pela simples negação (CIDREIRA, 2005, p. 39).

Os povos primitivos desconheciam completamente estes conceitos, ainda que suas indumentárias nos serviram como fonte histórica e como referência estética (CIDREIRA, 2005). Na Idade Média as pessoas adotaram a indumentária como prazer estético, pois antes deste tempo o vestuário sobrevivia sem a instabilidade e a temporalidade da moda, e que certamente não quis dizer mudanças, no entanto, permaneceu estabilizado durante séculos.

O vestuário feminino, na Idade Media, foi desenhado para sugerir a maternidade, com ênfase nos contornos redondos e generosos, nos materiais macios, e tendia a centrar o interesse nos seios e estômago. Energia, força e saúde eram consideradas atraentes, e eram expressas por meio de cores vivas e brilhantes e vestidas toaletes com curvas pronunciadas, frequentemente acomodando e valorizando a mulher grávida. Foi no início da Idade Moderna, especificamente durante o Renascimento, que se pode reconhecer a moda como sistema. Segundo Cidreira (2005), descobrindo o fascínio do vestuário enquanto peça alegórica, pura fantasia, que sugere a preocupação com o belo, o sublime, a sedução, o prazer. Vestir-se então no século XIV, passa a atender uma exigência, sobretudo, estética.

As reflexões sobre corpo e vestuário processam-se numa representação de profundas mudanças na civilização - costumes, valores, etc. Em qualquer caso, julga-se que as novas maneiras de pensar, sentir e agir o corpo são indicadores de uma mudança. Portanto, a história do corpo e do vestuário tem sempre uma história incompleta, tem sempre por fazer, é basicamente de natureza qualitativa, nem sempre dispõem materiais 
concretos que evidencie as interpretações desses assuntos, que sugerem uma confirmação concreta dos dados.

Segundo Hollander (1996), a mudança real no que as mulheres vestiam poderia ocorrer apenas quando todas as fantasias inconscientes mudassem seu tema, e aspectos especificamente femininos dela tivessem oportunidade de exercer um papel maior na receita da moda, e isto na verdade finalmente começou a acontecer no século XX.

\section{Fatores que influenciam a roupa para gestantes}

Pode-se dizer que o ser humano sofre contínuas mudanças físicas durante toda a vida e estas ocorrem de diversas maneiras. Há alterações do tamanho, proporções corporais, forma e peso, como é visto na mulher durante toda a gestação (IIDA, 2005).

No estado gravídico, as variações ocorrem principalmente, em torno do abdômen, embora o busto e os quadris também tenham uma alteração significante. Iida (2005) comenta que as mulheres grávidas aumentam a dimensão lateral do abdômen em $80 \%$ (de $16,5 \mathrm{~cm}$ para $29,7 \mathrm{~cm}$ ) no último mês de gravidez.

O corpo é o suporte da vestimenta. Segundo Souza (2006), o vestuário estabelece um espaço para conter o corpo. Essa espacialidade é determinada pela estrutura anatômica e mobilidade corporal, constituindo-se em volumes que aderem, aproximam-se e se afastam do corpo ou ainda se projetam além de seus limites. Esse espaço pode ser aferido: possui dimensões físicas de comprimento, largura e profundidade, cujas relações de proporção e resultado formal estão atrelados à natureza das atividades a serem ali acomodadas.

Segundo Luperini (2008) a gravidez é apontada como uma transição que faz parte do processo do desenvolvimento, já que envolve a necessidade de reestruturação em várias dimensões, como: mudança de identidade, redefinição dos papéis especialmente - da mulher.

Maldonado (1991) relata as predominantes oscilações de sentimentos que podem ocorrer em gestantes ao longo do período da gravidez. A autora afirma que no primeiro trimestre (do primeiro ao terceiro mês) é comum, pelo fato da mãe não conseguir sentir o feto concretamente e pelas alterações no esquema corporal, o sentimento de dúvida, de alegria, apreensão ou até mesmo rejeição. Pode haver também ao longo da gestação (mais especificamente no primeiro trimestre) fantasias de aborto, hipersonia, náuseas, 
vômitos, desejos e/ou aversões (especialmente por certos tipos de comida), aumento de apetite, oscilações de humor, aumento da sensibilidade e da irritabilidade.

Durante o segundo trimestre (do quarto ao sexto mês), desenvolve-se uma sensação de bem-estar. O medo de abortar já deverá ter desaparecido, e os desconfortos físicos do primeiro trimestre diminuídos (EDEN, 2010). Segundo Maldonado (1991), é marcado por alterações no desejo e desempenho sexual, alterações no esquema corporal, por uma possível introversão e passividade, mas - principalmente - pelo impacto dos primeiros movimentos fetais, os quais podem ser sentidos pela mãe, e com isso, parece haver personificação do feto.

Com relação ao terceiro trimestre de gestação Miranda e Abrantes (2003) mencionam que é um período no qual surgem sentimentos contraditórios. Eles relatam que com a aproximação do momento do parto, a mulher pode ficar tanto ansiosa e desejante que este momento chegue logo para que ela possa conhecer seu bebê, como desejar que a gravidez se estenda por mais um tempo, talvez por não se sentir preparada o suficiente para o parto, para os cuidados com o bebê ou para a amamentação.

\section{Materiais e Métodos}

A pesquisa se desenvolveu com uma amostra onze mulheres grávidas em idade adulta a partir de 19 anos, pertencentes de diferentes contextos sociais, que permitiram, por meio de Termo de Consentimento Livre e Esclarecido, a veiculação de suas imagens e de seus discursos para fins acadêmicos e científicos. Em contrapartida, foi-lhes assegurado o sigilo da identidade, através da escolha de pseudônimos nomeado pelas mesmas, que a partir de então serão usados no trabalho (Quadro 1). 
Quadro 1

\begin{tabular}{|c|c|}
\hline Pseudônimo & Faixa etária \\
\hline Elizabeth & 30 anos \\
Julia & 30 anos \\
Gabriela & 36 anos \\
Mirela & 34 anos \\
Cassandra & 29 anos \\
Amanda & 26 anos \\
Maria Clara & 28 anos \\
Aline & 19 anos \\
Elisa & 23 anos \\
Artemis & 28 anos \\
Beatriz & 26 anos \\
\hline
\end{tabular}

Distribuição Amostral por Pseudônimo e Idade

O processo metodológico que guiou as definições da amostra e coleta de dados deste trabalho foi baseado nos depoimentos das próprias gestantes, e as informações colhidas foram analisadas via métodos de análise qualitativa, em especial, a análise de conteúdo.

Foram coletadas informações sobre a identidade social e dados pessoais de cada depoente. Na Seção A, a grávida discorreu sobre sua roupa predileta, informando forma, cor, tipo de tecido, a aparência, a procedência, se está adequada ao seu tipo físico, sua identidade e estilo de vida, e na Seção B, a entrevistada atribuiu valores de 1 a 5, aos 38 Indicadores para o Consumo de Moda e Vestuário (ROCHA, 2007), onde 1 é o menos importante e 5 é o mais importante, em relação à sua Roupa Predileta.

Para cada uma das grávidas entrevistadas, foi elaborada uma Ficha de Acompanhamento onde foram registrados todos os episódios relacionados à pesquisa, como os agendamentos das entrevistas e as medições de seu corpo gravídico em mudança. Esta ficha tornou-se um instrumento de grande importância, pois ajudou a 
registrar outras informações e depoimentos que não puderam ser contemplados nos questionários.

\section{Análise Amostral}

Os dados sócio-culturais coletados apontaram que a maioria das gestantes entrevistadas é residente no município do Recife. Das onze mulheres pesquisadas, sete residiamm em Recife, duas residiam no município de Olinda, uma em Jaboatão dos Guararapes e outra em Moreno. Na identificação religiosa, a amostra apontou que três das onze mulheres foram identificadas como protestantes, três SUD's - Santos dos Últimos Dias, duas católicas, duas espíritas e uma declarou não ter religião. Com relação à descendência, cinco mulheres entrevistadas se declararam de descendência branca, duas negras, três pardas, uma que respondeu não saber ao certo sua descendência por se achar misturada. Os dados socioeconômicos amostrais referentes à variável Educação revelaram que, em 2010, quatro grávidas possuíam Ensino Médio Completo, três possuíam Superior Incompleto, duas Superior Completo, uma com Ensino Médio Incompleto e uma com Pós-Graduação - Mestrado.

A renda familiar bruta comprova que as entrevistadas pertencem a classes sociais distintas. Dos questionários de renda familiar bruta, três tinham renda situada no intervalo entre $\mathrm{R} \$ 727,00$ a $\mathrm{R} \$ 1195,00$; duas entre $\mathrm{R} \$ 3480,00$ a $\mathrm{R} \$ 6564,00$; duas entre $\mathrm{R} \$ 1196,00$ a $\mathrm{R} \$ 2013,00$; duas entre $\mathrm{R} \$ 9734,00$ ou mais; e uma entre $\mathrm{R} \$ 2014,00$ a $\mathrm{R} \$ 3479,00$, correspondendo as classes sociais entre média e média alta. Apesar dos dados coletados indicarem certa afluência econômica, podemos destacar que muita das mulheres não tinham ocupação ou renda fixa, por isso a renda familiar bruta declarada corresponde ao somatório dos que moravam com elas - esposo/companheiro, parentes, dentre outros/as.

\section{Características das Preferências de Vestuário}

É necessário comentarmos que há limitações na amostragem, pois nesse tempo de suas vidas as escolhas/preferências por vestuário vão de acordo com a sua morfologia e fisiologia atual. Sabendo que estamos falando de gestantes, essa amostragem é descrita com um número pequeno de entrevistadas, como também requer um período pequeno para a pesquisa, ou seja, o período gestacional de, no máximo, nove meses. 
Quando relacionamos os principais fatores decisivos de compra de vestuário, a análise apontou que a grande maioria das gestantes tem acesso a computador, facilitando-as terem acesso direto ao que acontece no mundo das notícias. Em relação a isso, as mesmas são influenciadas pelas celebridades que mais apreciam, principalmente pelo seu corpo ou pelo modo de vestir ou seu comportamento, dentre outros fatores.

Gisele Bündchen, por tudo que conseguiu e por ser linda. (Artemis, 28 anos)

Fátima Bernardes, por ser elegante e profissional. (Elizabeth, 30 anos) Xuxa, 'todas' as crianças amam. (Elisa, 23 anos)

Diante do exposto, lembramos que todas as três celebridades citadas acima tiveram suas gestações acompanhadas pela mídia e fãs.

\section{Características da Roupa Predileta}

Muitos motivos levam às pessoas em ter uma peça de vestuário em seu guardaroupa classificando-a como sua Roupa Predileta, ou seja, a favorita, a adorada. Seja por situações diversas (individuais ou coletivas) que influenciam o uso dessa roupa, sejam para demonstrar sua personalidade, ou então, seu estilo de vida. Neste sentido, a experiência descrita com uma roupa já testada e aprovada parece ser um diferencial para o desenvolvimento de novos produtos.

$\mathrm{Na}$ apresentação da Roupa Predileta, e de acordo com o encontrado, fez-se necessário classificarmos três diferentes categorias que justificam a escolha da Roupa Predileta das gestantes entrevistadas: Nova Roupa Predileta - adquirida na gravidez para ter um bom caimento e adequação do corpo à roupa; a Roupa Predileta em Uso aquela adquirida e utilizada antes da gravidez e que continua servindo durante o período gestacional, e, Roupa Predileta Encostada Temporariamente - que não cabe mais, porém, ainda continua sendo a favorita.

\section{Nova Roupa Predileta}

Das onze entrevistadas, cinco apontaram que sua Roupa Predileta foi adquirida durante a gravidez, pois para muitas das gestantes a roupa nesse determinado tempo deve ser confortável e adapte a seu corpo em transformação. 
A entrevistada Elizabeth, apresentou como sendo sua Roupa Predileta uma calça de malha sintética, preta (Figura 1a), com uma faixa que amarra no lado direito. Elizabeth informou que a calça prioriza o conforto, segurança devido a cor, pois disfarça um pouco a barriga e as medidas. A entrevistada ainda comenta que essa peça do vestuário pode ser usada depois da gravidez, apesar de ter sido comprada nesse momento de mudanças no seu corpo.

Comprei pelo aspecto visual, quando vesti também senti que era confortável, comprei no começo da gravidez no metrô de São Paulo em maio desse ano, no início da gravidez. Pensei na possibilidade de utilizá-la muitas vezes ao longo da gestação. (Elizabeth, 30 anos)

A entrevistada Julia, em sua declaração, mostrou como sua Roupa Predileta um vestido folgado simples, solto e longo de microfibra na cor preta (Figura 1b). Também informou que foi um presente antes da gravidez, e como não tem muitas roupas de gestante, usa constantemente a peça, e considera ainda a roupa confortável e prática, porque ele se adapta bem à barriga que vai crescendo.

"É confortável e deixa minha barriga bem definida." (Julia, 30 anos)

Figura 1

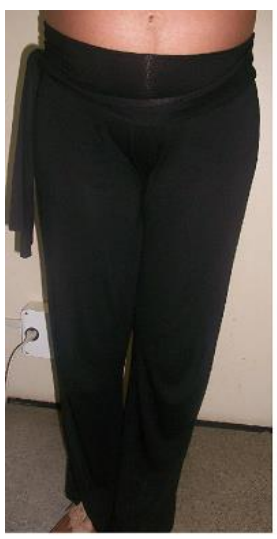

a) Elizabeth

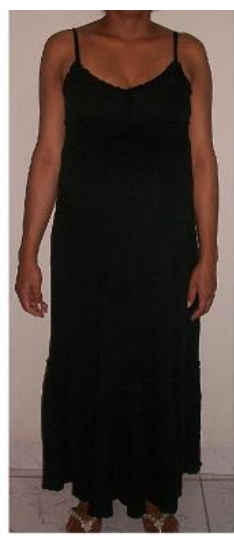

b) Julia

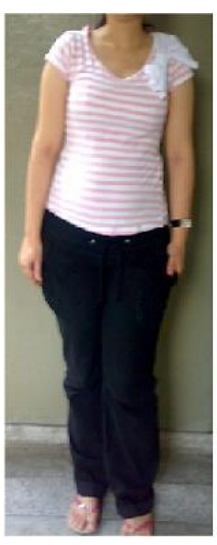

c) Amanda

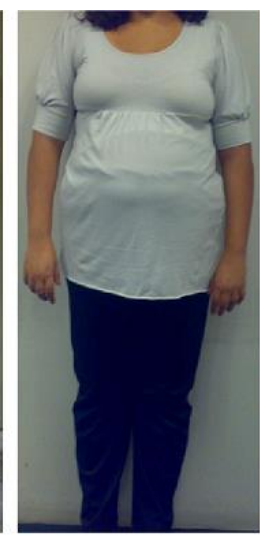

d) Elisa

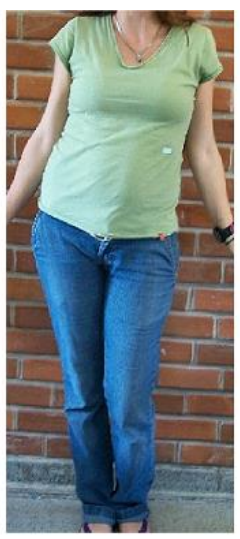

e) Artemis

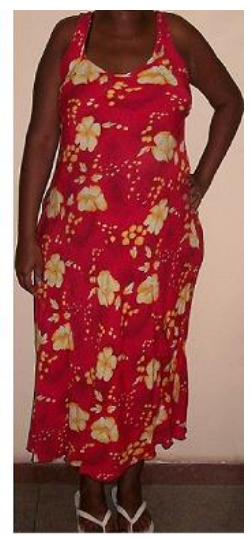

f) Gabriela

As Novas Roupas Prediletas e A Roupa Predileta em Uso das Entrevistadas

Para Amanda, a sua roupa predileta é um conjunto, composto por uma blusa de malha tipo batinha, listrada de cor rosa e branco com um laço branco que vai do busto ao ombro e calça preta de brim com muitos bolsos, a roupa tem uma modelagem que se adéqua ao corpo de uma gestante (Figura 1c). A entrevistada ainda descreveu que mesmo antes da gestação gostava muito de usar blusas e calças, ressaltando que 
continua a usar roupas do seu estilo, por isso permanece usando esses tipos de vestimentas também na gravidez.

É a que no momento de gestação me sinto melhor esteticamente. Quando fui comprar foi a que mais gostei. (Amanda, 26 anos)

A declaração de Elisa para sua roupa preferida vai além do conforto, pois alega que tem uma constante dificuldade em encontrar uma roupa que se adeque ao seu tipo físico, que é considerado por ela muito grande. Sua roupa predileta é considerada como a única que se adequou a seu corpo no momento, sendo uma batinha solta de malha mista, de cor cinza, apertada nos braços com franzido nos ombros e com um decote redondo no busto (Figura 1d). A entrevistada comprou a peça de um catálogo de roupas, ao comprar achou a blusa super confortável, pois foi a única roupa que tem o seu tamanho.

Aproveitei a promoção e comprei um monte dessas roupas, tenho de todas as cores que imaginar. (Elisa, 23 anos)

O estilo da roupa predileta de Artemis é considerado básico, com uma influência esportiva, calça jeans justa, escura sem apliques e camisetas confortáveis com cores fortes e/ou estampas geométricas, longas, geralmente de algodão - tecidos leves, "sem petróleo" e pouca tinta (Figura 1e). Segundo a entrevistada o seu estilo geralmente é comprado em lojas populares e de departamentos, consideradas boas e baratas. No entanto, ela busca conforto e praticidade, e declara que tem pouco tempo para pensar em produção visual e a sua gravidez a deixa cansada.

Tenho porte médio, mais levada ao atlético, e a minha condição financeira classe $C$. Sou prática e não tenho paciência para moda ou maquiagem; sem frescura para lavagem. (Artemis, 28 anos)

\section{A Roupa Predileta em Uso}

Das onze entrevistadas, apenas uma apontou que sua Roupa Predileta continua em uso durante a gravidez, pois ela se adapta bem ao seu corpo em transformação.

A roupa predileta de Gabriela é um vestido longo e folgado, de viscose estampado de cor vermelha (Figura 1f). Ela destacou sua roupa preferida como um vestido que já usava antes da gravidez e gosta muito dessa peça do vestuário. Ela considera que além do vestido dar uma aparência jovial, também lhe proporciona conforto. 
Além dele ser bastante adequado para gestante, ele também é confortável. (Gabriela, 36 anos)

\section{Roupa Predileta Encostada Temporariamente}

Das onze entrevistadas, cinco destacaram que sua Roupa Predileta não se adéqua mais ao seu corpo atual, motivo pelo qual intitulamos a categoria como Roupa Predileta Encostada Temporariamente. Nessas mulheres há um forte intento de que após a gestação essas peças caibam perfeitamente em seus corpos, será que o corpo volta ao normal? As roupas elencadas pelas gestantes se caracterizam pela estética quando vestidas no corpo, elevando a feminidade nas entrevistadas.

A roupa predileta elencada por Mirela é um vestido de malha na altura do joelho sem mangas, com estampado de cores básicas e de fácil combinação - preto com diversas estampas (Figura 2a). Há dois anos atrás, uma amiga que vende roupas a ofereceu para comprar, descreveu que só compra roupas que são adequadas ao seu corpo e que tenham um caimento perfeito, nesse caso antes da gravidez. Ela também descreveu que por ser acinturado, sua roupa predileta, não cabe mais em seu corpo gravídico, embora considere a roupa jovem e atual.

Me sinto arrumada e também confortável com ele. (Mirela, 34 anos)

Figura 2

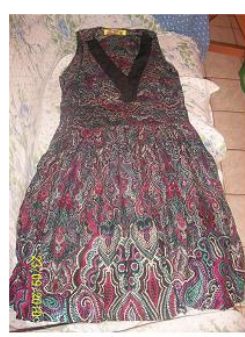

a) Mirela

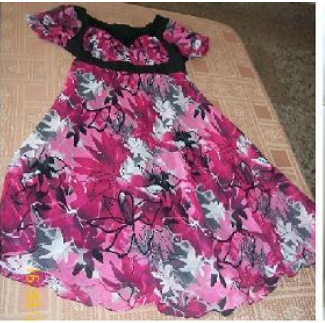

b) Cassandra

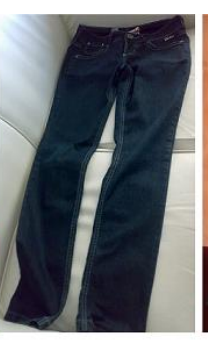

c) Maria Clara

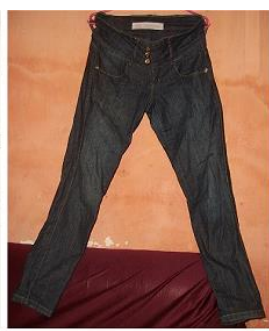

d) Aline

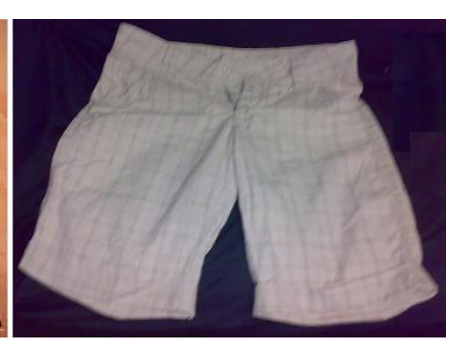

e) Beatriz

As Roupas Prediletas das Entrevistadas Temporariamente Encostadas

A entrevistada Cassandra mostrou um vestido folgado (godê) estampado floral com mangas, decote em forma de $\mathrm{U}$ e babados de renda, confeccionado em tecido de viscolycra com seda na parte do busto (Figura $2 b$ ). No caso desta peça, ela comprou o tecido e mandou confeccionar com o custo total de $\mathrm{R} \$ 50,00$. Ela ressaltou que o modelo do vestido pode ter um bom caimento em qualquer tipo físico feminino magra, gorda, alta e baixa. Lembrou ainda que sua roupa pode ser usada tanto para ir a 
um evento social de dia, como ir à igreja aos domingos. A entrevistada ainda declarou que tentou usar o vestido durante a sua gestação, porém ficou apertado, não sentindo mais à vontade e deixou de usá-lo temporariamente.

Adoro vestidos e este foi um modelo que eu escolhi o tecido como o modelo e tem um bom caimento. (Cassandra, 29 anos)

Maria Clara apresentou uma calça comprida de jeans com elastano, totalmente justa (skinny), de cor azul marinho sem estampas. Foi um presente de seu esposo, na época que ainda namoravam, da marca Colcci Jeanswear no valor de R $\$ 300,00$. Ela afirma que já gastou muito mais que isso numa peça de vestuário e destacou que vestia sua calça predileta muito bem antes da gestação, e porque engordou não dá mais, porém relatou que com toda a certeza voltará a usá-la após o nascimento do bebê (Figura 2c).

É uma roupa que faz parte do meu estilo. (Maria Clara, 28 anos)

A entrevistada Aline também escolheu uma calça jeans como sua roupa predileta, super justa e de cintura alta (Figura 2d). Comprou há um ano atrás de uma amiga que revendeu no valor de $\mathrm{R} \$ 160,00$. Para ela, a calça ficava muito bonita e vestia muito bem, e chamava muito atenção, porém pelo avançado da gestação está muito apertada.

Dá para eu usar aonde eu quiser ir. (Aline, 19 anos)

Para Beatriz, sua roupa predileta é uma bermuda jeans de cor xadrez clarinho bege e verde, na altura do joelho, nem justa nem folgada, com uma barra italiana. Ela declara que gosta do tecido ser leve, que pode ser usado em ambientes descontraídos, além do mais "tem charme" (Figura 2e). Ela ainda Informou que comprou numa loja de Departamento no valor de $\mathrm{R} \$ 60,00$ há quase dois anos atrás.

Acho que fica muito bonita e confortável, porém meu quadril alargou.

(Beatriz, 26 anos)

Podemos observar no Gráfico 1, os Indicadores que serviram de parâmetro para analisar a Roupa Predileta (Nova, Em Uso ou Encostada Temporariamente): valores tangíveis e intangíveis que estes tipos de roupas carregam para as gestantes entrevistadas.

Fica evidente que os motivos que fizeram essas onze mulheres gestantes terem como roupa predileta estas e não outras, visto que suas falas não trazem a exclusiva 
expressão da verdade. Em determinados discursos nota-se que dois ou mais poderiam ser os motivos para a tal escolha, principalmente pela inconstância de suas medidas atuais que gradativamente mudam no decorrer dos dias/meses.

$\mathrm{Na}$ tabulação dos dados é possível verificar que houve dezessete fatores mais importantes para explicar porque a roupa era predileta: Adequação Física; Aparência Etária; Beleza; Bem Estar; Caimento; Clima; Conforto; Convenções Morais; Cor; Durabilidade; Encantamento; Estilo Pessoal; Funcionalidade; Gosto; Humor/Astral; Qualidade; Tecido. Enquanto os menos privilegiados pela baixa pontuação são: Exposição do Corpo; Influência de Celebridade; Marca e Ousadia. 
Gráfico 1

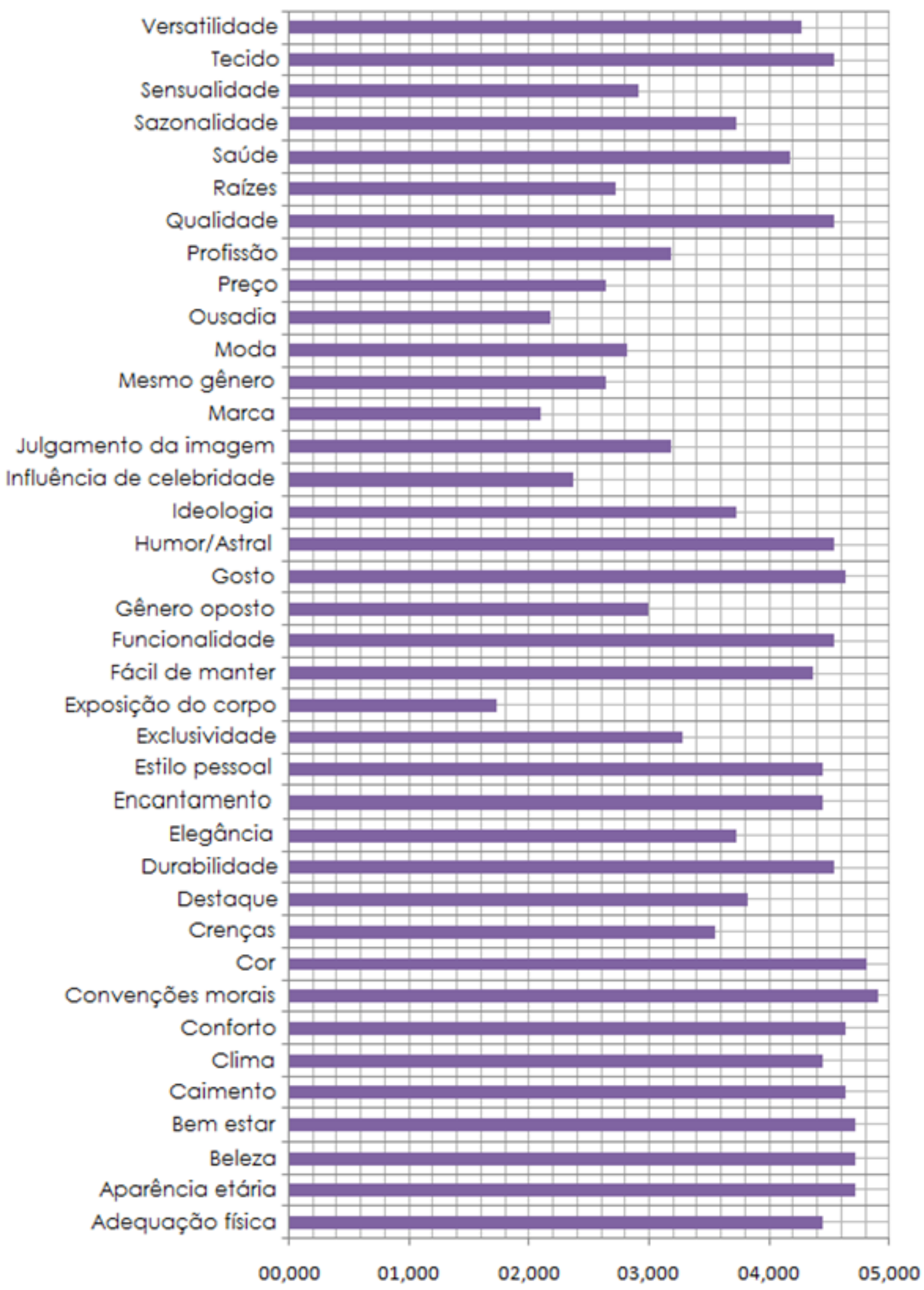

Média dos Indicadores para a Roupa Predileta segundo as Entrevistadas 
A diversidade na natureza dos Indicadores demonstra que, apesar do estado gravídico, as consumidoras sentem e experimentam contradições semelhantes àquelas mulheres em outras fases da vida. A existência de Indicadores que representam valores tangíveis e valores intangíveis indica que, independentemente da necessidade especial temporária, o vestuário para estas mulheres está carregado de significados, ou seja, dos elementos relacionados à moda.

\section{Considerações Finais}

Esse trabalho buscou o aprofundamento do conhecimento sobre a temática das relações existentes entre o vestuário e o estado gravídico em mulheres em idade adulta. As relações exploradas nesse trabalho abrem caminho para tantas outras questões que envolvem a temática, visto que as reflexões não se esgotam nesta pesquisa. No entanto, a busca da compreensão das emoções vestimentares a partir das características corporais das gestantes foi muito desafiadora. Para que essa pesquisa fosse realizada, foi necessário que uma troca simultânea de saberes entre as entrevistadas e a pesquisadora se consolidasse, muitas vezes trazendo abordagens não perceptíveis pelas próprias gestantes no seu cotidiano.

No mapeamento das preferências de consumo de moda-vestuário das gestantes, observamos que os resultados encontrados identificaram relações comuns entre as entrevistadas. Sobretudo, não podemos generalizar os resultados encontrados para todas as gestantes visto que a amostra foi pequena. No mesmo sentido, são prováveis que os resultados também não sejam os mesmos se as mulheres pesquisadas não estivessem em período gestacional. Ressaltamos, porém, que o recorte foi suficiente para uma pesquisa exploratória que investiga os fatores que podem interferir diretamente nas preferências vestimentares dos indivíduos por meio da sua morfologia e fisiologia atual.

$\mathrm{Na}$ apresentação da Roupa Predileta, e de acordo com o encontrado, foram classificadas três diferentes categorias que justificam a escolha da Roupa Predileta das gestantes entrevistadas: Nova Roupa Predileta, Roupa Predileta em Uso e Roupa Predileta Encostada Temporariamente. A escolha da Roupa Predileta objetivou explorar uma peça de roupa já testada, contendo, assim, uma grande carga objetiva ou racional. Como as roupas expressam um conjunto de elementos que consideram situações particulares do contexto vivido, nesse caso, as gestantes declararam priorizar o 
conforto e a segurança dos seus corpos. Vale salientar que, para algumas gestantes, a roupa predileta está encostada temporariamente, pois estava desconfortável em seu corpo gravídico.

O monitoramento dos Indicadores para o Consumo de Moda e Vestuário parece ser uma ferramenta eficaz para dar suporte ao desenvolvimento de novos produtos. É certo que há necessidade de redução no número de Indicadores quando da elaboração do briefing pela equipe de projeto, e portanto, o inquérito relacionado à roupa predileta pode auxiliar na captura dos elementos mais importantes para um público específico.

Essa pesquisa também promove algumas reflexões futuras: Será que as mulheres entrevistadas continuarão com a mesma percepção de seus corpos após terem acesso a este trabalho? Ou melhor, será que as mesmas mulheres estarão satisfeitas com seus corpos após a gravidez? Quais serão os fatores determinantes para suas próximas roupas prediletas?

Essas perguntas, assim como infinitas outras poderão surgir por meio da leitura deste trabalho, abrindo-se a oportunidade para que muitos profissionais atentem para a temática, ainda tão escassa de trabalhos que relacionem o corpo com necessidades especiais e a roupa, ou, para sermos mais precisas, as modificações corporais e o design do vestuário.

\section{Artigo recebido em Julho de 2015. Aprovado em Setembro de 2015 DOl:http://dx.doi.org/105965/1982615x08172016250}

\section{Referências}

CIDREIRA, Renata Pitombo. Os sentidos da moda: vestuário, comunicação e cultura. São Paulo: Annablume, 2005.

CRANE, Diana. A moda e seu Papel Social: Classe, gênero e identidade das roupas. Tradução: Cristina Coimbra. São Paulo: Editora Senac, 2006.

EDEN, Elizabeth. Alterações psicológicas durante a gravidez. - trad. HowStuffWorks Brasil, 2010. Disponível em: http://saude.hsw.uol.com.br/alteracoes-psicologicas-nagravidez1.htm ; Acesso: 17/ nov 2010

FISCHER-MIRKIN, Toby. $\boldsymbol{O}$ código de vestir: os significados ocultos da moda feminina. Rio de Janeiro: Editora Rocco, 2001.

FLÜGEL, J. C. A psicologia das roupas. São Paulo: Mestre Jou, 1966. 
HOLLANDER, Anne. O sexo e as roupas: a evolução do traje moderno. Rio de Janeiro: Rocco, 1996.

IIDA, Itiro. Ergonomia: projeto e produção. 2 ed. rev. e ampl. São Paulo: Blucher, 2005.

LUPERINI, Karina. Corporeidade gestante: o discurso de corpo de mulheres em idade adulta e madura e dos pais das crianças. Dissertação (mestrado) - UNIMEP Universidade Metodista de Piracicaba, Faculdade de Ciências da Saúde. Piracicaba: 2008 . http://www.unimep.br/phpg/bibdig/pdfs/2006/JFKXAPLOOOGW.pdf ; Acesso: 26/mar 2010 .

MALDONADO, M. T. P. Psicologia da gravidez: parto e puerpério. $12^{\mathrm{a}}$ edição. Petrópolis: Vozes, 1991.

MIRANDA, S. A.; ABRANTES, F. Ginástica para Gestante. $4^{\mathrm{a}}$ edição. Rio de Janeiro: Sprint, 2003.

ROCHA, Maria Alice Vasconcelos. Study of Consumer Clothing Behaviour and its Relevance to Successful Fashion Product Development. Tese de Doutoramento em Design de Moda (PhD in Fashion Design). Rochester, Reino Unido: University for the Creative Arts / University of Kent, 2007.

A roupa como expressão de comunicação. UFRPE - Apostila da

Disciplina de Vestuário: Departamento de Ciências Domésticas/DCD, 2010.

SOUZA, Patrícia de Melo. Modelagem tridimensional como implemento do processo de desenvolvimento do produto de moda. Dissertação (Mestrado em Design de Produto) - Faculdade de Artes, Arquitetura e Comunicação, Universidade Estadual Paulista - UNESP, Bauru, 2006. Disponível em: http://www.faac.unesp.br/posgraduacao/design/dissertacoes/ pdf/patricia.pdf ; Acesso: $19 /$ nov 2010

STEFANI, Patrícia da Silva. Moda e Comunicação: a indumentária como forma de expressão. Monografia (Graduação) - Curso de Comunicação Social, Universidade Federal de Juiz de Fora, FACOM, Juiz de Fora, 2005. Disponível em: http://www.facom.ufjf.br/projetos/2sem_2005/pdf/PSilva.pdf ; Acesso: 11/ out. 2010.

WILSON, Elizabeth. Enfeitada de sonhos: moda e modernidade. Rio de Janeiro: Edições 70, 1985. 